www.jmscr.igmpublication.org

Index Copernicus Value: 79.54

ISSN (e)-2347-176x ISSN (p) 2455-0450

crossrefDOI: https://dx.doi.org/10.18535/jmscr/v7i1.171

\title{
Effect of Age, Size and Site of Perforation on Surgical Outcome in Myringoplasty
}

\author{
Authors \\ Dr Anita Atal ${ }^{1}$, Dr Ankit Goyal ${ }^{2 *}$, Dr Bharti Solanki ${ }^{3}$, Dr Ashutosh Kayasth ${ }^{4}$ \\ Dr Mahendra Kuldeep ${ }^{5}$ \\ ${ }^{1,2}$ Final Year Postgraduate Student, Department of E.N.T., S.N.M.C., Jodhpur, Rajasthan, India \\ ${ }^{3}$ Professor, Department of E.N.T., S.N.M.C., Jodhpur, Rajasthan, India \\ ${ }^{4}$ First Year Postgraduate Student, Department of E.N.T., S.N.M.C., Jodhpur, Rajasthan, India \\ ${ }^{5} 2^{\text {nd }}$ Postgraduate Student, Department of Medicine, S.N.M.C., Jodhpur, Rajasthan, India \\ *Corresponding Author \\ Dr Ankit Goyal \\ Mobile no - 7017786510, Email: ankitchandragoyal@gmail.com
}

\begin{abstract}
Introduction: This prospective study was carried out for the evaluation of factors affecting the surgical results in Myringoplasty mainly age, size and site of perforation independent of cause of perforation.

Method: 60 patients were divided into 3 groups based on factors like age, size \& site of perforation. Surgical results of myringoplasty was measured on the basis of graft take rate and post operative hearing benefit.

Results: Graft take rate was maximum in the age group of 21- 25 years, perforations involving inferior and posterosuperior quadrants \& small sized perforations, while Graft take rate was minimum in the age group of more than 40 years, perforations involving all quadrant of tympanic membrane \& subtotal perforation. Maximum AB gap closure was seen in age group of 16-20 years, perforations involving Posteroinferior quadrant of tympanic membrane \& small perforations, while minimal AB gap closure was seen in 40 years age group, perforations involving anterior quadrant of tympanic membrane \& subtotal perforations.

Conclusion: From this study we concluded that age, site and size of tympanic membrane perforation affects surgical outcome after Myringoplasty.

Keywords: Myringoplasty, Graft takes rate, AB gap closure.
\end{abstract}

\section{Introduction}

Chronic suppurative otitis media is a long standing infection of a part or whole of the Middle ear cleft characterized by ear discharge and a permanent perforation and hearing loss. Tympanoplasty refers to any operation involving reconstruction of the tympanic membrane and/or the ossicular chain. Myringoplasty is a Tympanoplasty without ossicular reconstruction. ${ }^{1}$ In 1956, Zollner successfully used autologous fascia lata ${ }^{2}$. Temporal muscle fascia in myringoplasty was suggested for the first time by Wullstein in $1957 .^{3}$

Despite the high success rate and the routine nature of the procedure, the effect of many 
influencing factors remains unresolved which include the age of the patients, site of the perforation, size of the perforation, length of the ear has been dry prior to surgery, the presence of infection at the time of surgery and status of the opposite ear. ${ }^{4}$

This study analyzed a three factors known to affect surgical outcome so that it can be utilized for selecting candidates for surgery .

\section{Material and Methods}

This prospective study was conducted on 60 patients admitted with diagnosis of CSOM (tubotympanic type) who underwent myringoplasty using underlay temporal fascia graft for a period of 2 years (1.1.2014 to 31.12 2015).

Patients with chronic suppurative otitis media with tubotympanic type of disease with dry ear (inactive) for more than 1 month, age more than 10yrs, only conductive hearing loss, no previous history of ear surgery were included for study. Patients having wet ear, mixed hearing loss, tympanosclerosis and ossicular chain disorder, cholesteatoma (atticoantral type of CSOM) or systemic disease like Diabetes mellitus, hypertension, tuberculosis etc. were excluded from study . Patients with history of nasal allergy, other nasal diseases, throat problems were appropriately treated before taking for ear surgery. A detailed study of each patient including history, clinical examination, audiological evaluation, radiological examination and routine investigations were done.

Tympanic membrane is divided into four quadrants which are Anterosuperior (AS), Posterosuperior (PS), Anteroinferior (AI) and Posteroinferior (PI) respectively. Tympanic membrane perforation was quantified as small, medium, large and subtotal based on their sizes. Small central perforation involves a single quadrant, Medium size perforation involves two quadrants, large central perforation involves more than two quadrants \& subtotal perforation is a large defect surrounded by a completely intact annulus.

Myringoplasty was done using temporalis fascia by post aural approach under general anesthesia. Postoperatively the patients were discharged on 4nd-5rd post-operative day. Systemic antibiotics and antihistaminics were routinely administered for 7 days. Analgesics were prescribed symptomatically. A decongested nasal drops was prescribed for $2-3$ weeks. Meatal pack was removed after 3 weeks, neodrum was inspected, and patients were told to follow-up regularly at weekly intervals to note the uptake of graft for 3 months and 6 months. Surgical outcome of myringoplasty was measured on the basis of the condition of the graft taken or failure. Hearing improvement was assessed by closure of air -bone gap.

Data were analyzed using the chi-squared test and t-test on a statistical package (version 16.0; SPSS). A $\mathrm{P}<0.05$ was the level of significance.

\section{Results}

Table 1: Distribution of patients by age $(\mathrm{N}==60)$

\begin{tabular}{|l|c|c|c|}
\hline Age (yrs) & Male & Female & Total \\
\hline $10-15$ & 04 & 02 & 06 \\
\hline $\mathbf{1 6 - 2 0}$ & 11 & 10 & $\mathbf{2 1}$ \\
\hline $21-25$ & 07 & 06 & 13 \\
\hline $26-30$ & 04 & 05 & 09 \\
\hline $31-40$ & 06 & 03 & 09 \\
\hline$>40$ & 00 & 02 & 02 \\
\hline Total & 32 & 28 & 60 \\
\hline
\end{tabular}

The patients chosen were between age group 12 to 50 years. The maximum numbers of patients were between 16-20 years age group .

Table 2: Distribution of patients on the basis of perforation size $(\mathrm{N}=60)$

\begin{tabular}{|l|c|c|}
\hline Size of perforation & Number & Percentage \\
\hline Small & 05 & $8.33 \%$ \\
\hline Medium & $\mathbf{3 0}$ & $\mathbf{5 0 \%}$ \\
\hline Large & 22 & $36.66 \%$ \\
\hline Subtotal & 03 & $5 \%$ \\
\hline Total & 60 & $100 \%$ \\
\hline
\end{tabular}

Medium sized perforations were most common around $50 \%$. 
Table 3: Distribution of patients according to site of tympanic membrane perforation $(\mathrm{N}=60)$

\begin{tabular}{|l|c|c|}
\hline Site of perforation & Number & Percentage \\
\hline AI & $\mathbf{0 1}$ & $\mathbf{1 . 6 6}$ \\
\hline PI & 04 & $6.66 \%$ \\
\hline AI+PI & 12 & 20 \\
\hline AS +AI & 09 & 15 \\
\hline PS+PI & 09 & 15 \\
\hline AS +AI+PI & $\mathbf{1 6}$ & $\mathbf{2 6 . 6 6}$ \\
\hline AI+PI+PS & 05 & 8.33 \\
\hline AS+AI+PI+PS & 04 & $6.66 \%$ \\
\hline Total & 60 & $100 \%$ \\
\hline
\end{tabular}

Majority of cases 16 cases $(26.66 \%)$ were having perforation in (AS+AI+PI) quadrant, while minimum number of cases were having in AI quadrant of tympanic membranes $(1.66 \%)$.

Table 4: Relative frequency of graft take rate in different age groups

\begin{tabular}{|c|c|c|c|c|c|}
\hline \multirow[t]{2}{*}{ Age (in years) } & \multirow[t]{2}{*}{ No. of cases } & \multicolumn{2}{|c|}{ Graft condition } & \multirow{2}{*}{$\begin{array}{l}\text { Percentage of } \\
\text { Post op Success }\end{array}$} & \multirow[b]{2}{*}{$P$ value } \\
\hline & & Rejected & Taken & & \\
\hline $10-15$ & 6 & 01 & 05 & $83.33 \%$ & 0.20 \\
\hline $16-20$ & 21 & 01 & 20 & $95.23 \%$ & $<0.0001$ \\
\hline $21-25$ & 13 & 00 & 13 & $100 \%$ & 0.0001 \\
\hline $26-30$ & 9 & 01 & 08 & $88.88 \%$ & 0.032 \\
\hline $31-40$ & 9 & 02 & 07 & $77.77 \%$ & 0.162 \\
\hline$>40$ & 2 & 01 & 01 & $50 \%$ & 1.50 \\
\hline Total & 60 & 06 & 54 & $90 \%$ & $<0.0001$ \\
\hline
\end{tabular}

Graft rate was seen to be $100 \%$ in the age group of $21-25$ years while it was only $50 \%$ in the age group of more than 40 years.

Table 5: Relative frequency of graft take rate at different site of perforation

\begin{tabular}{|l|c|c|c|c|}
\hline \multirow{2}{*}{ Size of perforation } & \multicolumn{2}{|c|}{ Graft status } & \multirow{2}{*}{ Success Rate } & \multirow{2}{*}{ P value } \\
\cline { 2 - 3 } & Rejected & Taken & & \\
\hline AI & 00 & 01 & $\mathbf{1 0 0} \%$ & 1.000 \\
\hline PI & 00 & 04 & $\mathbf{1 0 0 \%}$ & 0.11 \\
\hline AI+PI & 00 & 12 & $\mathbf{1 0 0} \%$ & 0.003 \\
\hline AS +AI & 02 & 07 & $77.77 \%$ & 0.162 \\
\hline PS+PI & 00 & 09 & $\mathbf{1 0 0} \%$ & 0.002 \\
\hline AI+PI+PS & 00 & 05 & $\mathbf{1 0 0} \%$ & 0.05 \\
\hline AS +AI+PI & 02 & 14 & $87.50 \%$ & 0.002 \\
\hline AS+AI+PS+PI & 02 & 02 & $\mathbf{5 0} \%$ & 1.38 \\
\hline Total & 06 & 54 & $90 \%$ & $<0.0001$ \\
\hline
\end{tabular}

In our study, minimal $(50 \%)$ graft take rate was seen in perforation involving all quadrant of tympanic membrane (AS+AI+PS+PI) and maximal $(100 \%)$ graft take rate was seen in AI, PI $(\mathrm{AI}+\mathrm{PI}),(\mathrm{PS}+\mathrm{PI}),(\mathrm{PS}+\mathrm{PI}+\mathrm{AI})$ quadrants .

Table 6: Relative frequency of graft take rates in relation to size of perforation

\begin{tabular}{|l|c|c|c|c|}
\hline \multirow{2}{*}{ Size } & \multicolumn{2}{|c|}{ Graft status } & \multirow{2}{*}{$\begin{array}{c}\text { Percentage of graft } \\
\text { taken }\end{array}$} & P value \\
\cline { 2 - 3 } & Rejected & Taken & $\mathbf{1 0 0 \%}$ & 0.05 \\
\hline Small & 00 & 05 & $93.33 \%$ & $<0.0001$ \\
\hline Medium & 02 & 28 & $90 \%$ & $<0.0001$ \\
\hline Large & 02 & 20 & $\mathbf{3 3 . 3 3 \%}$ & 1.000 \\
\hline Subtotal & 02 & 01 & $90 \%$ & $<0.0001$ \\
\hline Total & 6 & 54 & & \\
\hline
\end{tabular}


The graft was taken up in medium sized perforation group is $93.33 \%$, while graft take rate of large and subtotal perforation were $90 \%$ and
$33.33 \%$ respectively. The graft take rate of small size perforation was highest $100 \%$.

Table 7: Correlation between age with AB Gap in pre \& post operated ear

\begin{tabular}{|c|c|c|c|c|c|}
\hline \multirow{2}{*}{$\begin{array}{l}\text { Age } \\
\text { (in years) }\end{array}$} & \multirow{2}{*}{$\begin{array}{l}\text { Preoperative } \\
\text { AB Gap } \\
\text { (in dB ) }\end{array}$} & \multicolumn{2}{|c|}{$\begin{array}{l}\text { Post Operative AB Gap of } \\
\text { operated ear } \\
\text { (in dB) }\end{array}$} & \multirow{2}{*}{$\begin{array}{l}\text { Air- Bone Gap } \\
\text { closure at } 6^{\text {th }} \\
\text { month of post } \\
\text { op } \\
\text { (dB) } \\
\end{array}$} & \multirow{2}{*}{$P$ value } \\
\hline & & $\begin{array}{l}\text { Post op 3th } \\
\text { Month }\end{array}$ & $\begin{array}{c}\text { Post op 6 } \\
\text { Month }\end{array}$ & & \\
\hline $10-15(n=6)$ & $29.16 \pm 4.31$ & $14.44 \pm 2.92$ & $11.10 \pm 6.63$ & $18.05 \pm 7.32$ & $<0.0001$ \\
\hline 16-20 $(n=21)$ & $28.41 \pm 3.00$ & $15.15 \pm 3.24$ & $10.32 \pm 4.36$ & $18.09 \pm 4.15$ & $<0.0001$ \\
\hline $21-30(\mathrm{n}=22)$ & $27.49 \pm 3.62$ & $16.51 \pm 3.29$ & $10.91 \pm 4.16$ & $16.58 \pm 6.03$ & $<0.0001$ \\
\hline $31-40(n=9)$ & $28.51 \pm 4.20$ & $19.44 \pm 4.85$ & $17.22 \pm 6.66$ & $11.29 \pm 7.67$ & 0.0004 \\
\hline$>40(n=2)$ & $30.83 \pm 5.89$ & $21.67 \pm 2.36$ & $20.8 \pm 3.51$ & $10.01 \pm 2.37$ & 0.163 \\
\hline
\end{tabular}

Maximum audiological benefit (Air- Bone closure $18.09 \pm 4.15 \mathrm{~dB})$ was seen in 16-20 years group and minimal audiological benefit (Air- Bone closure $10.01 \pm 2.37 \mathrm{~dB}$ ) was seen in more than 40 years group.

Table 8: Correlation in site of perforation with pre \& post operative AB Gap

\begin{tabular}{|c|c|c|c|c|c|}
\hline \multirow[b]{2}{*}{ Site of perforation } & \multirow{2}{*}{$\begin{array}{c}\text { Preoperative } \\
\text { AB Gap }\end{array}$} & \multicolumn{2}{|c|}{$\begin{array}{c}\text { Post-Operative AB Gap of } \\
\text { operated ear }\end{array}$} & \multirow{2}{*}{$\begin{array}{c}\text { Air- Bone Gap } \\
\text { closure at } 6^{\text {th }} \\
\text { months of post op } \\
\text { (in dB) }\end{array}$} & \multirow[b]{2}{*}{$P$ value } \\
\hline & & $\begin{array}{l}\text { Post op 3th } \\
\text { Month }\end{array}$ & $\begin{array}{l}\text { Post op 6 } \\
\text { Month }\end{array}$ & & \\
\hline $\mathrm{AI}(1)$ & $21.66 \pm 0.0$ & $18.34 \pm 0.0$ & $10.00 \pm .0$ & 11.67 & \\
\hline PI (4) & $28.74 \pm 4.38$ & $15.0 \pm 3.33$ & $7.91 \pm 1.59$ & $20.83 \pm 5.52$ & $<0.0001$ \\
\hline $\mathrm{AS}+\mathrm{AI}(\mathrm{n}=9)$ & $25.55 \pm 3.22$ & $17.77 \pm 3.53$ & $15.55 \pm 5.71$ & $9.99 \pm 6.34$ & 0.0001 \\
\hline $\mathrm{PS}+\mathrm{PI}(\mathrm{n}=9)$ & $27.77 \pm 2.88$ & $13.70 \pm 2.00$ & $7.41 \pm 2.06$ & $20.36 \pm 2.46$ & $<0.0001$ \\
\hline $\mathrm{AI}+\mathrm{PI}(\mathrm{n}=12)$ & $26.52 \pm 2.97$ & $15.69 \pm 3.51$ & $9.72 \pm 1.71$ & $16.80 \pm 3.85$ & $<0.0001$ \\
\hline $\mathrm{AS}+\mathrm{AI}+\mathrm{PI}(\mathrm{n}=16)$ & $29.89 \pm 2.46$ & $17.81 \pm 4.06$ & $14.58 \pm 6.12$ & $15.31 \pm 6.75$ & $<0.0001$ \\
\hline $\mathrm{AI}+\mathrm{PI}+\mathrm{PS}(\mathrm{n}=5)$ & $29.66 \pm 2.17$ & $15.33 \pm 4.31$ & $10.0 \pm 3.90$ & $19.66 \pm 5.31$ & $<0.0001$ \\
\hline $\mathrm{AS}+\mathrm{AI}+\mathrm{PI}+\mathrm{PS}(\mathrm{n}=4)$ & $33.33 \pm 3.59$ & $18.75 \pm 5.33$ & $17.91 \pm 7.37$ & $15.42 \pm 6.71$ & 0.006 \\
\hline Total & $28.24 \pm 3.58$ & $16.44 \pm 3.83$ & $12.0 \pm 5.56$ & & $<0.0001$ \\
\hline
\end{tabular}

Maximum Air- Bone closure $(20.83 \pm 5.52 \mathrm{~dB})$ was seen in perforation involving PI quadrant of tympanic membrane and minimal Air- Bone closure $(9.99 \pm 6.34 \mathrm{~dB})$ seen in perforation involving ( $\mathrm{AS}+\mathrm{AI})$ quadrant of Tympanic membrane.

Table 9: Correlation in size of perforation with pre \& post operative AB Gap

\begin{tabular}{|c|c|c|c|c|c|}
\hline \multirow[t]{2}{*}{ Size } & \multirow[t]{2}{*}{$\begin{array}{c}\text { Preoperative } \\
\text { AB Gap (in dB) }\end{array}$} & \multicolumn{2}{|c|}{$\begin{array}{l}\text { Post Operative AB Gap of } \\
\text { operated ear (in dB) }\end{array}$} & \multirow{2}{*}{$\begin{array}{l}\text { Air Bone Gap } \\
\text { closure at } 6 \text { th } \\
\text { Month of post } \\
\text { op }\end{array}$} & \multirow[t]{2}{*}{$P$ value } \\
\hline & & $\begin{array}{l}\text { Post op 3th } \\
\text { Month }\end{array}$ & $\begin{array}{l}\text { Post op } 6^{\text {th }} \\
\text { Month }\end{array}$ & & \\
\hline Small (5) & $27.33 \pm 4.94$ & $15.66 \pm 3.25$ & $8.33 \pm 1.66$ & $18.99 \pm 6.33$ & $<0.0001$ \\
\hline Medium (30) & $26.60 \pm 3.04$ & $15.72 \pm 3.42$ & $10.78 \pm 4.72$ & $15.82 \pm 5.98$ & $<0.0001$ \\
\hline Large (22) & $30.15 \pm 2.71$ & $17.04 \pm 4.14$ & $13.48 \pm 5.79$ & $16.66 \pm 6.60$ & $<0.0001$ \\
\hline Subtotal (3) & $32.22 \pm 3.46$ & $20.55 \pm 4.81$ & $19.43 \pm 8.21$ & $12.78 \pm 5.09$ & 0.066 \\
\hline
\end{tabular}

Hearing benefit was found to be correlated with the size of the perforation. As the size of the perforation increases, the Air- Bone closure was found to decrease post operatively. Maximum AirBone closure $(18.99 \pm 6.33 \mathrm{~dB})$ was found in small perforation, while minimal Air- Bone closure $(12.78 \pm 5.09 \mathrm{~dB})$ was found in subtotal perforation. 


\section{Discussion}

Three pre - operative factors (age, site and size of perforation of the tympanic membrane) were studied to see the surgical outcome which was measured on the basis of graft take rate and post operative hearing improvement.

In our study of 60 cases, $100 \%$ graft take rates were seen in 21-25 years age group. The hearing benefits were seen in more in age group 16-20 years. Probably as there are decrease chances of upper respiratory tract infection, adenoid hypertrophy, acute tonsillopharyngitis or any related illness in adult as compare to children / puberty, there by graft take is more in adult. As the age increase, the power of healing and regeneration decrease proportionately. So success rate is poor as age increase. Michael and Glasscock et al. (1982) ${ }^{5}$ report in their study of 1556 tympanic membrane grafting that there was no difference in take rate of graft based upon age of the patient. Vartiainen et al in $1985^{6}$ found that results in elderly patients were found to be as good as in younger patients.

In our study of 60 cases, graft take rate of small size perforation was highest $100 \%$. As the size of the perforation increases, the Air- Bone gap closure was found to decrease post operatively. This study contrast to the study conducted by Packer's ${ }^{7}$ in which it was found that in those with a larger hearing deficit pre operatively, benefited more than those with a minimal pre operative hearing loss. John B Booth (1973) ${ }^{\mathbf{8}}$ demonstrated that for perforations which involved less than $50 \%$ of tympanic membrane, higher closure rate were achieved than the perforation of more than $50 \%$. Adkins WY, White B (1984) ${ }^{9}$ in their study of 71 cases found high failure rate in graft take up in cases with near total or total perforation. Jackler Robert K, Schindler Robert A (1984) ${ }^{\mathbf{1 0}}$ in their study of 48 tympanoplasty cases found that patients with small sized perforation had high failure rate in comparison to other sizes.

In our study, Maximum graft rejection occurred in perforation which involving the all four quadrant of tympanic membrane. The maximum Air- Bone closure $(20.83 \pm 5.52 \mathrm{~dB})$ was seen in perforation involving PI quadrant of tympanic membrane and minimal Air- Bone closure $(9.99 \pm 6.34 \mathrm{~dB})$ seen in perforation involving ( $\mathrm{AS}+\mathrm{AI}$ ) quadrant of Tympanic membrane. There are no definite reports in literature relating the site of perforation of tympanic membrane with the hearing benefit in myringoplasty. Higher rate of surgical failure in patients with anterior perforations in comparison to posterior perforations may have been due to the more limited vascularization of the anterior part of the ear drum, limited access to this perforation as well as difficulty in graft placement. Halik, Smyth (1988) ${ }^{\mathbf{1 2}}$ in their study found higher risk of graft failure in anteroinferior quadrant because of poor visualization.

\section{Conclusion}

We concluded that age, site and size of tympanic membrane perforation affects surgical outcome in Myringoplasty, but other factor are also need to be studied which can affect overall results .

\section{Bibliography}

1. George G Browning. Chronic otitis media. Scott brown's Otorhinolaryngology, head and neck surgery 7 th edition. 2008; 237: 3421-22.)

2. Zollner F. Panel of myringoplasty. Second workshop on reconstructive middle ear surgery. Arch Otol. 1963; 78:301.

3. Wullestin H. Theory and practice of tympanoplasty. Laryngoscope. 1956; 66: 1076-95.

4. Warren Y, Adkins MD. Type I tympanoplasty: influencing factors. Laryngoscope 1984; 94: 916 - 918.

5. Suresh Palukuri, Venu Gopala Raju S. V. One Year Follow up Study on Audiological Profile in Chronic Otitis Media Patients, After 'Type 1 Tympanoplasty'.Internation Journals of recent trends in Science \& technology, ISSN 2277-8109,Volume 9,Issue 3,2014 pp 343-345. 
6. Clinical audiovestibulometry by Dr. Anirban Biswas. $3^{\text {rd }}$ edition. Pg no.1-55.

7. Niteshore MS,Rita Z.Influence of eustahian tube function in outcome of endoscopic type 1 tympanoplasty .IOSR Jouranal mar 2014,volume 13;26-28.

8. Jackler RK, Schindler RA. Role of mastoid in tympanic membrane reconstruction. Laryngoscope 1984; 94:495-500.

9. Ludman H. Applied anatomy. 5th ed. In: Mawson's Diseases of the ear, Ludman H, ed. London: Edward Arnold Publication; 1988. pp. 17-44.

10. Wright A. Anatomy and ultra structure of the human ear. 6th ed. In: Scott-Brown's Otolaryngology, Gleeson M, ed. Oxford: Butterworth-Heinemann Publication 1997; 1:1/1/11-1/1/25.

11. Sakagami M, Maeda A, Node M, Sone M, Mishiro Y. Long-term observation on hearing change in patients with chronic Otitis media.Auris Nasus Larynx. 2000; 27(2):117-20.

12. Prasnsuk $S$ and Hinchelffe R. Tympanic membrane perforation: Descriptors and hearing levels in otitis media. Audiology 1982; 21: 43-51. 